\title{
Digital Hazards for Feeding and Eating: What We Know and What We Don't
}

\author{
Konstantinos loannidis ${ }^{1,2,3,4}$ (ID $\cdot$ Samuel R Chamberlain ${ }^{5,6}$
}

Accepted: 1 June 2021 / Published online: 15 July 2021

(C) The Author(s) 2021

\begin{abstract}
Purpose of Review We aimed to accrue recent evidence exploring effects of modern online activities (e.g., Internet use) on feeding and eating disorder symptoms, and related traits. We examined available evidence to ascertain any direct influences from online activities on feeding and eating disorders, thereby shedding light on putative mechanisms by which those influences may occur. Recent Findings Many facets of problematic usage of the Internet correlate cross sectionally with eating disorder and related psychopathology. There is evidence to suggest that significant effects do exist in the direction of specific Internet activities contributing to eating disorder symptoms, viewed dimensionally. Putative mechanisms are discussed. However, a significant number of eating disorder phenotypes and Internet-related activities remain under-researched.

Summary Specific facets of engagement with the online environment appear to confer risk for feeding and eating problems, evidence being strongest for non-clinical studies using dimensional measures. More research is required to rigorously confirm causal effects, including in patients meeting formal diagnostic criteria for eating disorders. We also highlight the need for highquality evidence to explore how eating disorder phenotypes are commonly as well as uniquely affected by different online activities. Such research is needed in order that scientific understanding in this area can be translated to protect those most at risk of disordered eating, including through changes in public health approaches and clinical practice.
\end{abstract}

Keywords Anorexia nervosa $\cdot$ Bulimia nervosa $\cdot$ Binge eating disorder $\cdot$ Eating disorder $\cdot$ Internet addiction $\cdot$ Social networking site $\cdot$ Social media $\cdot$ Problematic Internet use

This article is part of the Topical Collection on Psychiatry in the Digital Age

Konstantinos Ioannidis ioannik@doctors.org.uk

1 Department of Psychiatry, University of Cambridge, Cambridge, UK

2 Cambridge and Peterborough NHS Foundation Trust, Cambridge, UK

3 Department of International Health, Care and Public Health Research Institute, Maastricht University, Maastricht, Netherlands

4 Eating Disorder Service, Addenbrookes Hospital, Hills Road, Cambridge CB2 0QQ, UK

5 Department of Psychiatry, University of Southampton, Southampton, UK

6 Southern Health NHS Foundation Trust, Southampton, UK

\section{Introduction}

Eating disorders (EDs) confer an important health burden for societies worldwide [1,2]. Anorexia nervosa (AN) has the highest morbidity and mortality of all mental illnesses [3] and a significant lifetime prevalence, depending on diagnostic criteria and population under study [4]. Bulimia nervosa (BN), binge eating disorder (BED) [5], and other less studied known diagnostic categories, e.g., avoidant-restrictive food intake disorder (ARFID), are considered more common and are often underdiagnosed [6]. Restrictive eating, typical of AN, is often interspersed with binge eating or purging or excessive exercise behaviors and cross-diagnostic interplay of symptoms is very common [7], while more often than not, individuals swap between ED diagnostic classifications during their lifetime. Specifically, since the introduction of Diagnostic and Statistical Manual Version 5 (DSM-5) criteria for feeding and eating disorders [8], the prevalence of diagnostic groups is considered to have increased among all main diagnostic categories [9]. Eating disorders have a complex partially 
known pathophysiology which implicates multiple layers of socio-cultural and biological contextual variables [7]. There is paucity of experimental research in the field [10] and most things we know about the pathophysiology of EDs derive from "quasi-experimental" studies and randomized controlled trials (RCTs). While RCTs include a manipulated component that separates the intervention and the control arm, often several factors are targeted simultaneously through comprehensive treatment programs; this approach does not necessarily allow for the identification of causal effects with adequate enough precision to specify effects to fine detail [10]. While we have been building our understanding of the gene $\times$ environment interaction to identify risk factors for EDs towards the end of the twentieth century, efforts were made through observational research to understand the influences of popular media (paper media, advertisements, TV) on eating disorder risk factors. Pooled evidence suggested that women in particular are suffering from a hazardous influence from exposure to popular media in terms of body dissatisfaction, internalization of thinness ideals, and disordered eating [11, 12]. Exposure to beauty ideals coupled with an internalization of media mandates led to a socio-cultural body ideal mismatch. The latter has been considered a piece of the puzzle in the gene $\times$ environment interaction driving ED pathophysiology [13].

In the 1980s, a mighty force was born: the world-wide-web. It went from a whimsical idea to dominating real life communication, entertainment, and work in less than four decades, and has now shaped our lives irreversibly. While the essential and extremely valuable applications of the Internet in daily life are irrefutable, maladaptive forms of engagement with the online environment, encompassing a variety of activities (e.g., overuse of social media, streaming media, gaming, gambling, pornography [14•] has been associated with marked functional impairment $[15,16 \bullet \cdot$. The term problematic usage of the Internet (PUI) was coined to describe such dysfunctional engagement with multiple facets of Internet-based activities [16••]. PUI is now linked with poorer health, worse social, vocational, or academic outcomes or lower quality of life [16-18]. Since 2010, and given the previously mentioned concerning influences of media on eating disorder outcomes, significant concern arose within researchers, clinicians, and carers about those suffering from eating disorders, as to whether specific engagement with online content would impact on the development, course and management of eating disorders across the life span. A number of observational and experimental studies were performed since in attempt to disentangle effects and described the relevant relationships [19•*].

\section{New and Interesting Findings}

Research in the last decade started by exploring the membership in pro-anorexia forums (consumption and engagement in
"Pro-ANA" web-based content) [20] as those became very popular among anorexia sufferers. A few important steps towards understanding the role of PUI in ED pathophysiology were made, when Facebook use was found to prospectively predict an increase in drive for thinness 2 years later [21••], whereas receiving negative feedback through Facebook interactions was found to negatively associate with disordered eating attitudes [22]. Social networking site (SNS) use also predicted an increase in body dissatisfaction [23]. These results supported a causal hypothesis of the role that social media may have in eating disorders. However, such effects of SNS on ED were not identified in other studies [24]. Being exposed to pro-ED content or "fitspiration" content (media content aimed to inspire towards fitness activity or a fit body ideal) or regular popular social media (which often contain dieting, fitness, or other-appearance-focused content) as opposed to neutral conditions (e.g., viewing travel images or spending time reading encyclopedia entries online) seems to bear a degree of risk towards the development of mood and self-esteem difficulties that fuels EDs. Those experimental conditions were tested to show the "PUI condition" associating stronger with lower appearance self-esteem [25] and higher ED symptomatology [26-29]; those with appearance comparison traits were more prone to low mood effects from exposure to social media $[30,31]$. Another important aspect of engaging with the online content is the exposure to manipulated content, as this has the potential of creating unrealistic expectations of appearance and beauty. Under experimental conditions, selfphoto editing led to increased negative mood and body (facial) dissatisfaction, with higher levels of editing leading to more dissatisfaction. Furthermore, enhancement-free images seem to have less effect on body dissatisfaction, suggesting that self-photo manipulation may be playing a role in body dissatisfaction effects [32•,33]. While PUI $\times$ EDs interactions have been more explored in adult participants under experimental conditions, $\mathrm{AN}$ and $\mathrm{BN}$ are considered to sometimes have their beginnings in adolescence or earlier in life. The effects of appearance-focused gaming vs. ED-neutral gaming were assessed in young girls: those exposed to appearancefocused gaming had higher body dissatisfaction [34•]. This essentially represents a form of replication work from physical world experiments to the online environment; pre-pubertal girls exposed to Barbie doll play have high internalized thin ideals [35] and reduced food intake [36]; appearance-focused online gaming may influence EDs through a mechanistically similar fashion. This is a critically important point while online gaming in children and adolescents is growing as a cultural norm in developed societies, in which EDs are also more prevalent.

While activity tracking apps and fitness apps have become very popular among the eating disorder community, problematic usage of the Internet was shown to partially mediate the relationship between sensation-seeking impulsivity and eating 
disorders with high exercise levels [37]. Additionally, problematic usage of the Internet was found to partially mediate the link between obsessionality and eating disorders with high exercise levels [37]. Usage of fitness and calorie-tracking apps has correlated with eating disorder and related psychopathology both in males and females [38-40]. It is possible that in the background of particular latent traits of impulsivity or obsessionality/compulsivity, exposure to calorie or fitness apps may trigger problematic behaviors (e.g., excessive exercise) and potentially contribute to the development of clinically significant levels of ED in those who are vulnerable. However, those are outcomes of online surveys with various methodological limitations and disallow the drawing of any causal inferences.

Another developing area of interest has been the investigation of how dating sites may be influencing eating disorder and related psychopathology. Dating sites put emphasis on physical appearance and sharing of image-based content. As such, the individual is invited to judge others by their image while eliciting judgment on themselves. By creating this content, the individual engages in a process known as selfobjectification [41]; however, self-objectification may also occur in other forms of social and popular media. Selfobjectification is moderately correlated with disordered eating in meta-analysis (Pearson's $r=0.39,53$ cross-sectional studies), with larger effect sizes identified in females [42••]. Dating sites use has been cross sectionally associated with eating disorder symptomatology in various quantitative and qualitative studies [43-46].

A less well-understood aspect of engagement with the online environment is the one in which the user is subjected to harassment behavior, also known as cyberbullying. Experiencing cyberbullying through social media is considered to have not only debilitating effects on mental health in general [47], but also significant correlations with body dissatisfaction, negative body perception, and lower self-esteem $[48,49]$. The culture of body shaming has sparked a heated debate around whether such an approach can be deemed hazardous for the obesity population as it may well be for the eating disorder populations [50]. A quasi-experimental field study showed that fat-shaming events on social media could have putative snowball effects on the anti-fat attitudes in the wider population, the effects increasing with the notoriety of the event [51]. Body shaming can masquerade as essential public health messaging or as an essential component in the coach-athlete relationship [52], but essentially may constitute a form of emotional maltreatment [52]. While cyberbullying constitutes a form of maltreatment occurring in the online environment, it is possible that its effects may be detrimental for the individual's global mental health, rather than being ED specific. However, experiencing body shaming, regardless of whether the individual is victimized themselves in the event or not, may have specific effects on self-apprehension of weight, shape, or appearance, body dissatisfaction, or foster unhelpful anti-fat attitudes, which may be strong precursors for the development of EDs. Furthermore, it may promote stigma towards EDs, which can hinder the likelihood of affected individuals accessing timely help, and/or engaging fully with treatment, thereby worsening clinical outcomes [53]. For males, it may be even worse, as they need to battle against toxic masculinity and a well-established societal stigma (also present in the medical community) which promotes stereotypes of gender and sexual orientation in relation to those suffering from EDs.

\section{Trends and Developments}

While a substantial portion of the quantitative literature supports the notion that significant positive correlations exist between various facets of PUI and eating disorder and related psychopathology [19], those observational studies have focused on either precursor risk factors for eating disorders (e.g., the thin-ideal internalization, appearance comparisons, perfectionistic personality traits, loneliness, socio-cultural body ideal mismatch, self-objectification) or eating disorder symptoms which, on their own merits, do not necessarily constitute clinically significant levels of formal mental health disorder (e.g., body dissatisfaction, drive for thinness, dietary restraint, drive for muscularity) (see Figure 1).

Equally important is the fact that many of those personality dimensions, risk factors, and symptoms are trans-diagnostic, e.g., perfectionism is common not only in AN but also in obsessive compulsive personality disorder; e.g., body dissatisfaction and drive for muscularity are common not only in EDs (mainly AN and BN) but also in body dysmorphic disorder. Thin-ideal internalization (ITI) is common in AN and BN. The trans-diagnostic nature of those symptoms, together with a paucity of clinicallevel ascertainment in the literature, does not yet provide the necessary confidence to rigorously confirm causality between hazardous levels of PUI and occurrence of formal EDs. It is furthermore unclear how different facets of ED would be impacted differentially; thus, specific PUI behaviors like consumption of "thinspiration" content via SNS might be hazardous towards $\mathrm{AN}$ or $\mathrm{BN}$ outcomes, while other ED categories, e.g., BED or ARFID, where there is less presence of ITI may not be affected. Furthermore, cyberbullying victimization may affect differentially patients at higher BMIs (e.g., BED sufferers) through experiences of body shaming, or those who struggle to comprehend nuances of the online media social context (e.g., those who may have AN and autistic spectrum disorder comorbidity or other deficits in their theory of mind) and might be more vulnerable to cyber-harassment.

Moreover, it is less understood how some of the clinical phenotypes of ED are related to PUI. An interesting case series of ARFID and Internet gaming disorder (IGD) 


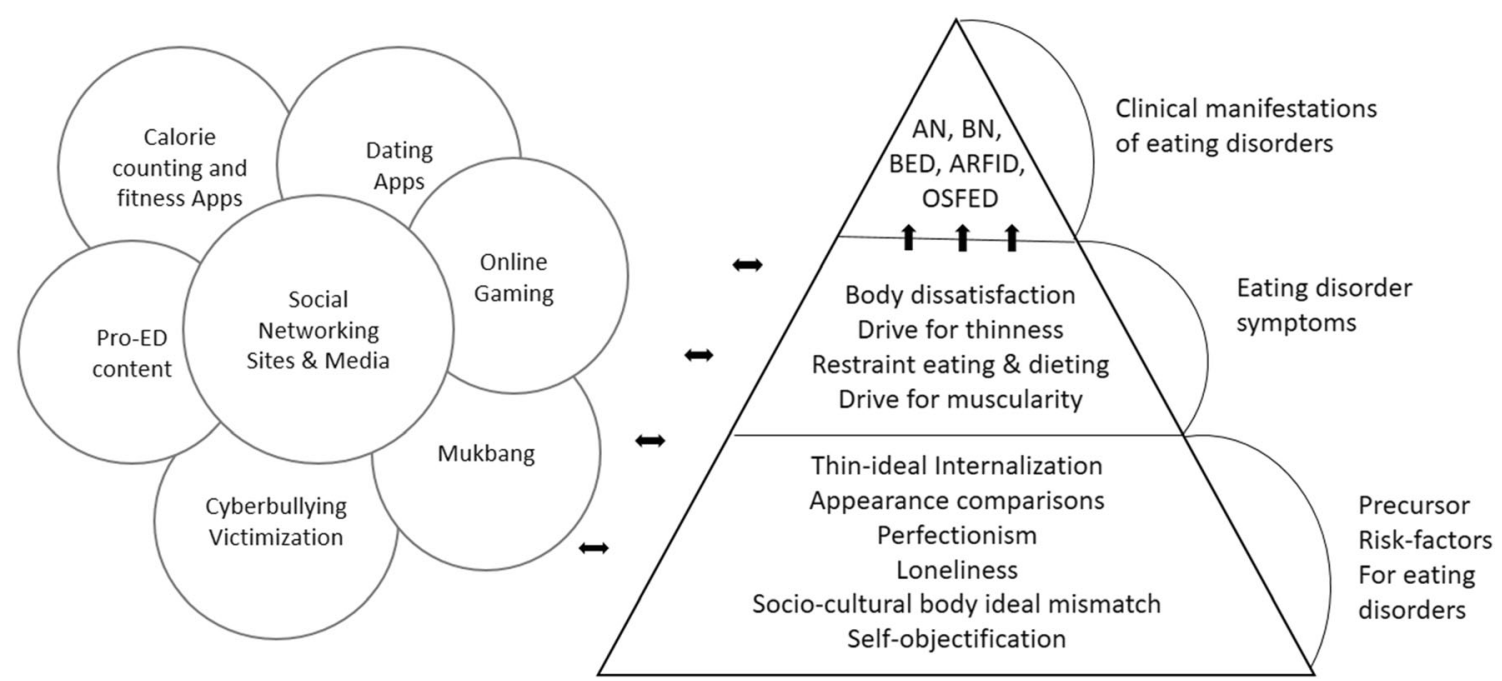

Fig. 1 Example illustration of the relationship between multiple facets of Internet usage and risk factors, precursors for feeding and eating disorders, as well as eating disorder symptoms

comorbidity was published [54] suggesting that both ARFID and IGD manifesting as coping strategies (a method of emotional regulation) to those avoidant of emotional distress. The relationship between Internet gaming and EDs is less understood, but there are examples in which body shaming and fatness have been used in video games to associate the obese male or female body with evilness, disability, monstrosity, and horror [55]. Such games are played by hundreds of million users worldwide and have the potential of having a substantial influence in the socio-cultural attitudes towards obese body types, potentially adding to weight-related stigma [56].

Finally, research has explored how the digital medium can be used to potentially promote a healthier body image; for example, an experimental study showed exposure to parody images of thin-ideal celebrities was associated with higher body satisfaction, when compared to exposure to the actual thin-ideal image [57]; self-disclaimers show little effectiveness in altering body image influences [58]. Further research is warranted to further understand how technology can be harnessed to promote a healthy relationship with someone's own body, nutrition, and exercise. Identification of vulnerable populations (e.g., via algorithmic/machine learning approaches, with appropriately rigorous statistical methodologies including cross-validation and independent replication) seems to be an important first step, which can then be followed by targeted ED-specific resilience promoting content. Apps, podcasts, and health resources already exist aiming to promote ED recovery to those seeking digital solutions to treatment and online delivery of psychotherapy has become the new norm during the COVID-19 pandemic. Most of those processes are currently at a preliminary stage, including how they can translate to real life applications, notwithstanding the major ethical considerations relevant to this process that involve, but not exhaustively, privacy, confidentially, and informed consent.

\section{Insights}

While the online environment continues to advance in many profound but also intricate ways, research attention has shifted to other facets of engagement with the online milieu, including, but not exhaustively, the consumption of image-based content through social media and image-based gaming, and even more recently the utilization of fitness-tracking/calorie-tracking applications (Apps), dieting Apps, dating Apps, and mukbang streaming consumption (mukbang is further explained below). A recent meta-analysis supported the fact that a variety of PUI facets are important for the understanding of digital hazards for feeding and eating [19]. Critically, while SNS have been relatively better studied, the use of activity and fitness tracking Apps, calorietracking Apps, and dating Apps, as well as cyberbullying experiences, may be playing a role in the link between PUI and eating disorder and related psychopathology.

\section{Controversy and Debate}

Another growing trend has been the investigation towards the understanding of mukbang as an emerging online behavior since 2014. Mukbang ("muk-bang" or "meokbang") is a Korean portmanteau term for "eating broadcast" and usually involves a host preparing and eating typically large amounts of food, while leisurely interacting with an audience in an online streaming platform. By some self-reports, mukbang has been regarded to have both beneficial (e.g., preventing binge eating episodes, reducing loneliness) and negative sequalae (triggering restrained eating or loss of control over eating) on eating disorder symptoms [59•]. It is possible that mukbang may be a fun, leisure, and intimate experience for a large portion of the population; millions engage with the streaming content daily and professional mukbang 
Table 1 Problematic usage of the Internet and eating disorders, and preliminary recommendations for public health and clinical care
Preliminary recommendations for public health and clinical care

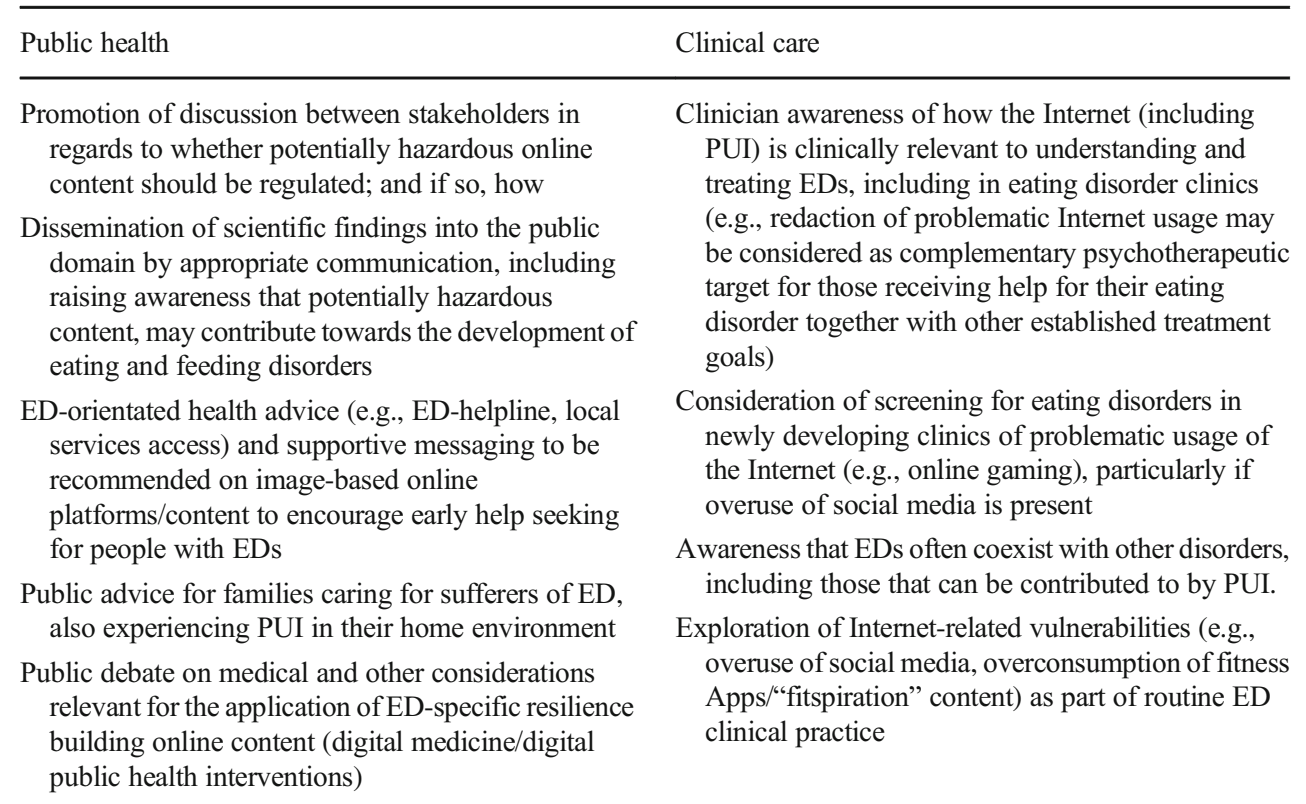

streaming is reportedly very profitable for the individual. On the other hand, it may create a platform for patients with AN to engage with food without consuming it, thus missing out on essential nutrition leading to self-neglect, or trigger binging episodes with untoward consequences [60]. It is a well-known fact that ED sufferers, even those at very low BMIs (e.g., AN), are "food lovers" and are generally much more fascinated by food preparation and consumption as compared to the general population. Thus, the fact that mukbang viewing is positively correlated with EDs is not a surprise [61], particularly when the observed behaviors are not ascertained at a maladaptive or clinical level. Anecdotal reports suggest that on occasion mukbang viewing promotes recovery practices [62]; therefore, it is still debatable whether consuming mukbang is a problematic behavior. Greater research-driven understanding is needed before any causal links are drawn; in approaching the mukbang phenomenon in a confirmatory and atheoretical fashion, we risk overpathologizing the behavior, an existing risk in behavioral addictions research in general [63].

\section{Conclusion}

We have discussed here specific facets of engagement with the online environment bear risk for feeding and eating problems viewed largely using dimensional measures in nonclinical settings. Experimental and prospective studies support a potential causal role for the engagement with social media leading to higher levels of body dissatisfaction and internalization of the thin ideal. The role of self-objectification, appearance comparison, impulsivity/compulsivity, or the socio- cultural body ideal mismatch is relatively unexplored from a mechanistic perspective, particularly in terms of the interaction of those concepts with a variety of relatively distinct online behaviors (e.g., consumption of pro-ED content, calorietracking/fitness apps, dating sites, gaming, mukbang streaming or watching, experiencing cyberbullying victimization). More longitudinal and experimental research is required to ascertain specific effects, simulating conditions of the various aspects of potentially hazardous online engagement towards the potential development of eating disorder psychopathology and to further clarify how research findings can best be translated into public health and clinical arenas (e.g., see Table 1), in order to optimally protect those who are vulnerable to developing disordered eating symptoms, or experiencing exacerbations thereof.

Acknowledgements We are indebted to all the researchers and health workforce who have supported ourselves and our society during these testing times.

Funding Dr Chamberlain's involvement in this research was funded by a Wellcome Trust Clinical Fellowship (110049/Z/15/Z). Dr Chamberlain previously consulted for Promentis. He receives stipends from Elsevier for journal editorial work. Authors received no funding for the preparation of this manuscript. The other authors report no financial relationships with commercial interest relevant to the content of this manuscript.

\section{Declarations}

Human and Animal Rights and Informed Consent This article does not contain any studies with human or animal subjects performed by any of the authors. 
Open Access This article is licensed under a Creative Commons Attribution 4.0 International License, which permits use, sharing, adaptation, distribution and reproduction in any medium or format, as long as you give appropriate credit to the original author(s) and the source, provide a link to the Creative Commons licence, and indicate if changes were made. The images or other third party material in this article are included in the article's Creative Commons licence, unless indicated otherwise in a credit line to the material. If material is not included in the article's Creative Commons licence and your intended use is not permitted by statutory regulation or exceeds the permitted use, you will need to obtain permission directly from the copyright holder. To view a copy of this licence, visit http://creativecommons.org/licenses/by/4.0/.

\section{References}

Papers of particular interest, published recently, have been highlighted as:

- Of importance

• Of major importance

1. Austin SB. A public health approach to eating disorders prevention: it's time for public health professionals to take a seat at the table. BMC Public Health [Internet]. 20129 [cited 2021 Jan 9];12(1):854. Available from: https://bmcpublichealth.biomedcentral.com/ articles/10.1186/1471-2458-12-854

2. Erskine HE, Whiteford HA, Pike KM. The global burden of eating disorders. Current Opinion in Psychiatry. 2016;29:346-53.

3. Arcelus J, Mitchell AJ, Wales J, Nielsen S. Mortality rates in patients with anorexia nervosa and other eating disorders. Arch Gen Psychiatry [Internet]. 2011 [cited 2019 Feb 18];68(7):724. Available from: http://www.ncbi.nlm.nih.gov/pubmed/21727255

4. Smink FRE, Van Hoeken D, Hoek HW. Epidemiology of eating disorders: incidence, prevalence and mortality rates. Curr Psychiatry Rep. 2012 Aug;14(4):406-14.

5. Kessler RC, Berglund PA, Chiu WT, Deitz AC, Hudson JI, Shahly $\mathrm{V}$, et al. The prevalence and correlates of binge eating disorder in the World Health Organization World Mental Health Surveys. Biol Psychiatry [Internet]. 2013 [cited 2021 Jan 9];73(9):904-14. Available from: /pmc/articles/PMC3628997/?report=abstract

6. Eddy KT, Thomas JJ, Hastings E, Edkins K, Lamont E, Nevins CM, et al. Prevalence of DSM-5 avoidant/restrictive food intake disorder in a pediatric gastroenterology healthcare network. Int $\mathrm{J}$ Eat Disord [Internet]. 2015 [cited 2021 Mar 12];48(5):464-70. Available from: https://pubmed.ncbi.nlm.nih.gov/25142784/

7. Treasure J, Zipfel S, Micali N, Wade T, Stice E, Claudino A, et al. Anorexia nervosa. Nature Reviews Disease Primers. 2015;1:1-21.

8. American Psychiatric Association. Feeding and Eating Disorders [Internet]. Diagnostic and Statistical Manual of Mental Disorders (DSM-5). 2013 [cited 2020 Feb 22]. Available from: https://web. archive.org/web/20150501013951/http://www.dsm5.org/ Documents/Eating Disorders Fact Sheet.pdf

9. Lindvall Dahlgren C, Wisting L, Rø Ø. Feeding and eating disorders in the DSM- 5 era: a systematic review of prevalence rates in non-clinical male and female samples [Internet]. Vol. 5, Journal of Eating Disorders. BioMed Central Ltd.; 2017 [cited 2021 Jan 30]. Available from: /pmc/articles/PMC5745658/?report=abstract

10. Glashouwer KA, Brockmeyer T, Cardi V, Jansen A, Murray SB, Blechert J, Levinson CA, Schmidt U, Tchanturia K, Wade TD, Svaldi J, Giel KE, Favaro A, Fernández-Aranda F, Friederich HC, Naumann E, Treasure JL, Tuschen-Caffier B, Vocks S, Werthmann $\mathrm{J}$ Time to make a change: a call for more experimental research on key mechanisms in anorexia nervosa. Eur Eat Disord Rev [Internet]. 2020 [cited 2021 Mar 12];28(4):361-7. Available from: https://onlinelibrary.wiley.com/doi/abs/10.1002/erv.2754.

11. Grabe S, Ward LM, Hyde JS. The role of the media in body image concerns among women: a meta-analysis of experimental and correlational studies. Psychol Bull [Internet]. 2008 [cited 2020 Jun 22];134(3):460-76. Available from: https://pubmed.ncbi.nlm. nih.gov/18444705/

12. Derenne JL, Beresin E V. Body image, media, and eating disorders [Internet]. Vol. 30, Academic Psychiatry. Springer; 2006 [cited 2021 Mar 20]. p. 257-61. Available from: https://link.springer. com/article/10.1176/appi.ap.30.3.257

13. Cash TF. The influence of sociocultural factors on body image: searching for constructs. Clin Psychol Sci Pract [Internet]. 2005 [cited 2021 Mar 12];12(4):438-42. Available from: http://doi.apa. org/getdoi.cfm?doi=10.1093/clipsy.bpi055

14. Ioannidis K, Treder MS, Chamberlain SR, Kiraly F, Redden SA, Stein DJ, et al. Problematic internet use as an age-related multifaceted problem: evidence from a two-site survey. Addict Behav [Internet]. 2018 [cited 2020 Feb 22];81:157-66. Available from: http://www.ncbi.nlm.nih.gov/pubmed/29459201 This is the first investigation to demonstrate problematic usage of the Internet as a multifaceted, age-related problem using a novel and comprehensive statistical approach.

15. Young KS. Internet addiction : the emergence of a new clinical disorder. Publ Cyber Psychol Behav. 1998;1(3):237-44.

16.• Fineberg N, Demetrovics Z, Stein D, Ioannidis K, Potenza M, Grünblatt E, et al. Manifesto for a European research network into Problematic Usage of the Internet. Eur Neuropsychopharmacol. 2018. https://doi.org/10.1016/J.EURONEURO.2018.08.004. This is a major review paper of problematic usage of the Internet as a theoretical construct led by an international consortium of experts.

17. Kuss D, Griffiths M, Karila L, Billieux J. Internet addiction: a systematic review of epidemiological research for the last decade. Curr Pharm Des [Internet]. 2014 [cited 2020 Aug 1];20(25):402652. Available from: https://pubmed.ncbi.nlm.nih.gov/24001297/

18. Floros GD, Ioannidis K. Editorial: The impact of online addiction on general health, well-being and associated societal costs. Front Public Health. 2021;9:318.

19.• Ioannidis K, Taylor C, Holt L, Brown K, Lochner C, Fineberg NA, et al. Problematic usage of the internet and eating disorder and related psychopathology: a multifaceted, systematic review and meta-analysis. Neurosci Biobehav Rev [Internet]. 2021 [cited 2021 Mar 19];125:569-81. Available from: https://linkinghub.elsevier. com/retrieve/pii/S0149763421001160 This is the most recent meta-analysis of problematic usage of the Internet and eating disorder and relating psychpathology integrating all quantitative research in the field.

20. Rodgers RF, Skowron S, Chabrol H. Disordered eating and group membership among members of a pro-anorexic online community. Eur Eat Disord Rev [Internet]. 2012 [cited 2020 Jun 21];20(1):912. Available from: http://doi.wiley.com/10.1002/erv.1096.

21.• Tiggemann M, Slater A. Facebook and body image concern in adolescent girls: a prospective study. Int J Eat Disord [Internet]. 2017 [cited 2020 Apr 28];50(1):80-3. Available from: http://doi. wiley.com/10.1002/eat.22640 This is an important prospective study demonstrating effects of SNS use on eating disorder and related psychopathology.

22. Hummel AC, Smith AR. Ask and you shall receive: desire and receipt of feedback via Facebook predicts disordered eating concerns. Int J Eat Disord [Internet]. 2015 [cited 2020 Jun 21];48(4): 436-42. Available from: https://pubmed.ncbi.nlm.nih.gov/ 25060558/

23. de Vries DA, Peter J, de Graaf H, Nikken P. Adolescents' Social network site use, peer appearance-related feedback, and body 
dissatisfaction: testing a mediation model. J Youth Adolesc [Internet]. 2016 [cited 2020 Jun 21];45(1):211-24. Available from: https://link.springer.com/article/10.1007/s10964-015-0266-4.

24. Ferguson CJ, Muñoz ME, Garza A, Galindo M. Concurrent and prospective analyses of peer, television and social media influences on body dissatisfaction, eating disorder symptoms and life satisfaction in adolescent Girls. J Youth Adolesc [Internet]. 2014 Jan [cited 2020 Jun 21];43(1):1-14. Available from: https://pubmed.ncbi. nlm.nih.gov/23344652/

25. Theis F, Wolf M, Fiedler P, Backenstrass M, Kordy H. Essstörungen im Internet: Eine experimentelle Studie zu den Auswirkungen von Pro-Essstörungs- und Selbsthilfewebsites. Psychother Psychosom Med Psychol [Internet]. 2012 [cited 2020 Jun 21];62(2):58-65. Available from: https://pubmed.ncbi.nlm. nih.gov/22334087/

26. Mabe AG, Forney KJ, Keel PK. Do you "like" my photo? Facebook use maintains eating disorder risk. Int $\mathrm{J}$ Eat Disord [Internet]. 2014 [cited 2020 Jun 21];47(5):516-23. Available from: https:/onlinelibrary.wiley.com/doi/full/10.1002/eat.22254.

27. Prichard I, Kavanagh E, Mulgrew KE, Lim MSC, Tiggemann M. The effect of Instagram \#fitspiration images on young women's mood, body image, and exercise behaviour. Body Image. 2020;33:1-6.

28. Tiggemann M, Zaccardo M. "Exercise to be fit, not skinny": The effect of fitspiration imagery on women's body image. Body Image [Internet]. 2015 [cited 2020 Jun 21];15:61-7. Available from: https://pubmed.ncbi.nlm.nih.gov/26176993/.

29. Brown Z, Tiggemann M. Attractive celebrity and peer images on Instagram: effect on women's mood and body image. Body Image [Internet]. 2016 [cited 2020 Jun 21];19:37-43. Available from: https://pubmed.ncbi.nlm.nih.gov/27598763/.

30. Fardouly J, Diedrichs PC, Vartanian LR, Halliwell E. Social comparisons on social media: the impact of Facebook on young women's body image concerns and mood. Body Image. 2015;13: 38-45.

31. Anixiadis F, Wertheim EH, Rodgers R, Caruana B. Effects of thinideal instagram images: the roles of appearance comparisons, internalization of the thin ideal and critical media processing. Body Image. 2019;31:181-90.

32. . Tiggemann M, Anderberg I, Brown Z. Uploading your best self: selfie editing and body dissatisfaction. Body Image. 2020;33:17582 This is an important recent study investigating body dissatisfation effects through manipulated media content.

33. Tiggemann M, Zinoviev K. The effect of \#enhancement-free Instagram images and hashtags on women's body image. Body Image. 2019;31:131-8.

34. Slater A, Halliwell E, Jarman H, Gaskin E. More than just child's play?: an experimental investigation of the impact of an appearance-focused Internet game on body image and career aspirations of young girls. J Youth Adolesc [Internet]. 2017 [cited 2020 Jun 21];46(9):2047-59. Available from: https://pubmed.ncbi.nlm. nih.gov/28316057/ This is an important recent study demonstrating effects of appearance-focused gaming on body image.

35. Dittmar H, Halliwell E, Ive S. Does Barbie make girls want to be thin? the effect of experimental exposure to images of dolls on the body image of 5- to 8-year-old girls. Dev Psychol [Internet]. 2006 [cited 2021 Mar 19];42(2):283-92. Available from: /record/200603514-007

36. Anschutz DJ, Engels RCME. The effects of playing with thin dolls on body image and food intake in young girls. Sex Roles [Internet]. 2010 [cited 2021 Mar 19];63(9-10):621-30. Available from: /pmc/ articles/PMC2991547/

37. Ioannidis K, Hook RW, Grant JE, Czabanowska K, RomanUrrestarazu A, Chamberlain SR. Eating disorders with over-exercise: a cross-sectional analysis of the mediational role of problematic usage of the internet in young people. J Psychiatr Res [Internet]. 2020 [cited 2021 Jan 10];132. Available from: https://pubmed.ncbi.nlm.nih.gov/33189357/

38. Embacher Martin K, McGloin R, Atkin D. Body dissatisfaction, neuroticism, and female sex as predictors of calorie-tracking app use amongst college students. J Am Coll Heal [Internet]. 2018 [cited 2020 Jun 21];66(7):608-16. Available from: https:// pubmed.ncbi.nlm.nih.gov/29405860/

39. Linardon J, Messer M. My fitness pal usage in men: associations with eating disorder symptoms and psychosocial impairment. Eat Behav [Internet]. 2019 [cited 2020 Jun 21];33:13-7. Available from: https://pubmed.ncbi.nlm.nih.gov/30772765/

40. Levinson CA, Fewell L, Brosof LC. My Fitness Pal calorie tracker usage in the eating disorders. Eat Behav [Internet]. 2017 [cited 2020 Jun 21];27:14-6. Available from: https://pubmed.ncbi.nlm.nih.gov/ 28843591/

41. Calogero RM, Davis WN, Thompson JK. The role of selfobjectification in the experience of women with eating disorders. Sex Roles [Internet]. 2005 [cited 2021 Mar 21];52(1-2):43-50. Available from: https://link.springer.com/article/10.1007/s11199005-1192-9

42.• Schaefer LM, Thompson JK. Self-objectification and disordered eating: a meta-analysis [Internet]. Vol. 51, International Journal of Eating Disorders. John Wiley and Sons Inc.; 2018 [cited 2021 Mar 26]. p. 483-502. Available from:/pmc/articles/PMC6002885/ This is an important recent meta-analysis showing the link between disordered eating and self-objectification.

43. Griffiths S, Murray SB, Krug I, McLean SA. The contribution of social media to body dissatisfaction, eating disorder symptoms, and anabolic steroid use among sexual minority men. Cyberpsychology, Behav Soc Netw [Internet]. 2018 [cited 2020 Jun 21];21(3):149-56. Available from: http://www.liebertpub. com/doi/10.1089/cyber.2017.0375.

44. Rodgers RF, Campagna J, Attawala R, Richard C, Kakfa C, Rizzo C. In the eye of the swiper: a preliminary analysis of the relationship between dating app use and dimensions of body image. Eat Weight Disord [Internet]. 2019 [cited 2020 Jun 21];1-5. Available from: https://link.springer.com/article/10.1007/s40519-019-00754-0.

45. Tran A, Suharlim C, Mattie H, Davison K, Agénor M, Austin SB. Dating app use and unhealthy weight control behaviors among a sample of U.S. adults: a cross-sectional study. J Eat Disord [Internet]. 2019 [cited 2020 Jun 26];7(1):16. Available from: https:/jeatdisord.biomedcentral.com/articles/10.1186/s40337-0190244-4.

46. Filice E, Raffoul A, Meyer SB, Neiterman E. The influence of Grindr, a geosocial networking application, on body image in gay, bisexual and other men who have sex with men: An exploratory study. Body Image. 2019;31:59-70.

47. Kelly Y, Zilanawala A, Booker C, Sacker A. Social media use and adolescent mental health: findings from the UK Millennium cohort study. EClinicalMedicine. 2018;6:59-68.

48. Kenny U, Sullivan L, Callaghan M, Molcho M, Kelly C. The relationship between cyberbullying and friendship dynamics on adolescent body dissatisfaction: a cross-sectional study. J Health Psychol [Internet]. 2018 [cited 2020 Jun 21];23(4):629-39. Available from: http://www.ncbi.nlm.nih.gov/pubmed/28810374

49. Marco JH, Tormo-Irun MP, Galán-Escalante A, Gonzalez-García C. Is Cybervictimization associated with body dissatisfaction, depression, and eating disorder psychopathology? Cyberpsychology, Behav Soc Netw [Internet]. 2018[cited 2020 Jun 21];21(10):611-7. Available from: /record/2018-52995-004.

50. Kar P. Partha Kar: Dieting and body shaming. BMJ (Online). 2019;364. https://doi.org/10.1136/bmj.11222.

51. Ravary A, Baldwin MW, Bartz JA. Shaping the body politic: mass media fat-shaming affects implicit anti-fat attitudes. Personal Soc Psychol Bull [Internet]. 2019 [cited 2021 Mar 19];45(11):1580-9. 
Available from: http://journals.sagepub.com/doi/10.1177/ 0146167219838550 .

52. McMahon J, McGannon KR, Palmer C. Body shaming and associated practices as abuse: athlete entourage as perpetrators of abuse. Sport Educ Soc [Internet]. 2021 [cited 2021 Mar 19]; Available from: https://www.tandfonline.com/doi/abs/10.1080/13573322. 2021.1890571.

53. Puhl R, Suh Y. Stigma and eating and weight disorders. Curr Psychiatry Rep [Internet]. 2015 [cited 2021 Mar 19];17(3). Available from: https://pubmed.ncbi.nlm.nih.gov/25652251/.

54. Hadwiger AN, Middleman AB, Pitt PD. Case series: gaming vs. eating - comorbidity of ARFID and IGD. Eat Weight Disord [Internet]. 2019 [cited 2021 Mar 13];24(5):959-62. Available from: https://pubmed.ncbi.nlm.nih.gov/30788778/.

55. Sarah S. Body horror as body shaming: fatness and monstrosity in video games. 2018 [cited 2021 Mar 19]; Available from: http:// www.digra.org/wp-content/uploads/digital-library/DIGRA_2018_ paper 33.pdf.

56. O'Keeffe M, Flint SW, Watts K, Rubino F. Knowledge gaps and weight stigma shape attitudes toward obesity [Internet]. Vol. 8, Lancet Diab Endocrinol. Lancet Publishing Group; 2020 [cited 2021 Mar 19]. p. 363-5. Available from: www.thelancet.com/ diabetes-endocrinology.

57. Slater A, Cole N, Fardouly J. The effect of exposure to parodies of thin-ideal images on young women's body image and mood. Body Image. 2019;29:82-9.

58. Livingston J, Holland E, Fardouly J. Exposing digital posing: the effect of social media self-disclaimer captions on women's body dissatisfaction, mood, and impressions of the user. Body Image. 2020;32:150-4.
59•. . Strand M, Gustafsson SA. Mukbang and disordered eating: a netnographic analysis of online eating broadcasts. Cult Med Psychiatry [Internet]. 2020 [cited 2021 Mar 19];44(4):586-609. Available from: /pmc/articles/PMC7497418/ This is an important recent publication on mukbang using a netnographic approach.

60. Donnar G. 'Food porn' or intimate sociality: committed celebrity and cultural performances of overeating in meokbang. Celebr Stud [Internet]. 2017 [cited 2021 Mar 19];8(1):122-7. Available from: https://www.tandfonline.com/doi/abs/10.1080/19392397.2016. 1272857.

61. Kircaburun K, Yurdagül C, Kuss D, Emirtekin E, Griffiths MD. Problematic mukbang watching and its relationship to disordered eating and Internet addiction: a pilot study among emerging adult mukbang watchers. Int J Ment Health Addict [Internet]. 2020 [cited 2021 Mar 19];1-10. Available from: https://doi.org/10.1007/ s11469-020-00309-w

62. Holness J. How Mukbang Videos Helped Me with My Eating Disorder | Her Campus. 2018. https://www.hercampus.com/ school/kent-state/how-mukbang-videos-helped-me-my-eatingdisorder. Accessed 19 Mar 2021.

63. Billieux J, Schimmenti A, Khazaal Y, Maurage P, Heeren A. Are we overpathologizing everyday life? A tenable blueprint for behavioral addiction research. J Behav Addict [Internet]. 2015 [cited 2021 Mar 20];4(3):119-23. Available from:/pmc/articles/PMC4627665/

Publisher's Note Springer Nature remains neutral with regard to jurisdictional claims in published maps and institutional affiliations. 